\title{
Constructor of a marvellous canon
}

\author{
George Szpiro weighs up a life of John Napier, who gifted science with logarithms.
}

\section{I} $n$ Romanian playwright Eugène Ionesco's The Lesson, a professor asks a student to multiply 3,755,998,251 by 5,162,303,508. To his amazement, the answer comes quick as a shot: 19,390,002,844,219,164,508. The student declares that she had "learnt all possible results of all possible multiplications by heart".

If only it were that simple. (Indeed, the student got it wrong: the answer is $19,389,602,947,179,164,508$.) Multiplication is computationally complex. The number of mathematical operations required to add two numbers grows linearly with the number of digits involved, but in multiplication using simple arithmetic the number of operations grows with the square of the number of digits. Computer algorithms now simplify this, but in centuries past multiplications were the bane of scientific research. The seventeenth-century astronomer Johannes Kepler, for instance, had to perform thousands of them to compute the positions of celestial objects.

His task would have been much more difficult had it not been for a discovery more than a decade before by mathematician John Napier: logarithms. Tables of these thenmysterious numbers meant that two figures could be multiplied by adding their logathrithms. In John Napier, maths writer Julian Havil traces the life and work of the man who presented us with this gift 400 years ago.
Napier was born in Edinburgh in 1550, 14 years before Galileo. Little is known about his youth and education except that he travelled, presumably in Europe, and returned to Scotland a scholar at 21 . He became a gentleman farmer, theologian and politician as well as a mathematician. A passionate intellec-

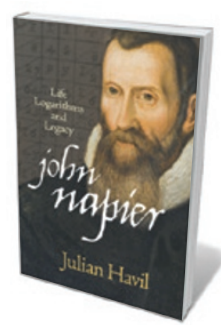

John Napier: Life, Logarithms, and Legacy JULIAN HAVIL Princeton University Press: 2014 tual, he often paced the countryside deep in thought in a dark cloak - his academic gear - which led neighbours to believe that he was in league with the devil. His groundbreaking book on logarithms, Mirifici Logarithmorum Canonis Descriptio, was published to little fanfare in 1614. It garnered less attention in his era than his 1593 blockbuster on the dangers of Catholicism, A Plaine Discovery of the Whole Revelation of St. John.

Descriptio consists of tables of logarithms and instructions on how to use them, in particular for multiplications and divisions in trigonometry, by adding and subtracting their entries. Within years of its publication, English mathematician William Oughtred

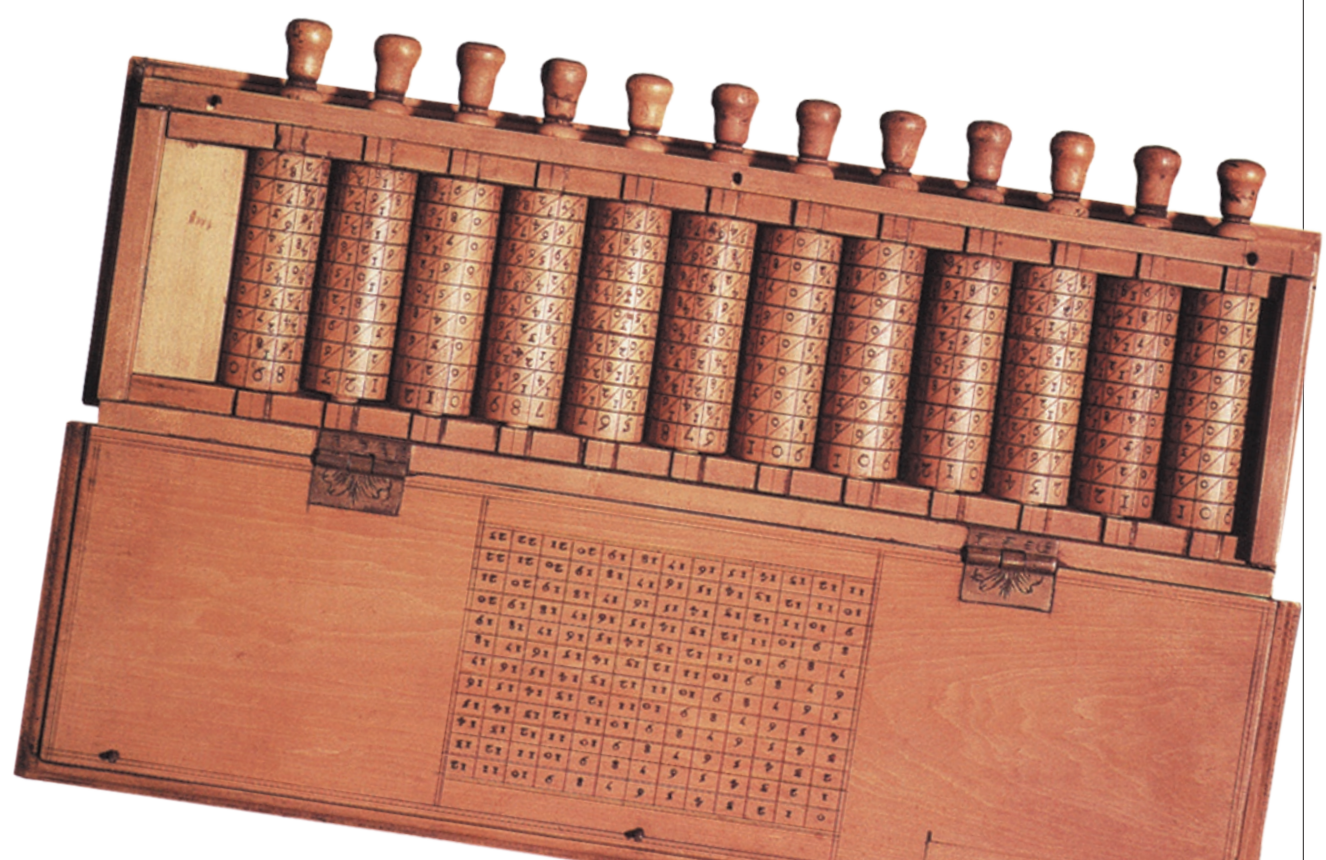

used Napier's logarithms to invent the slide rule, which remained indispensable for science, engineering and economics until the advent of the pocket calculator in the 1970s.

Napier published Descriptio without revealing how he had arrived at the logarithms. That secret was exposed only in Mirifici Logarithmorum Canonis Constructio, published after his death by his son Robert and friend Henry Briggs (to whom we owe the common logarithm to base ten). In Constructio, we find that Napier had discovered the numbers by considering two objects moving at different speeds along straight lines, and establishing a relationship between their locations at every moment. The most salient feature of logarithms is that they are needed to work out $x$ in equations of the form $10^{x}=1,000$. (In this case, $x=\log _{10}(1,000)=3$.)

However, it took more than a century to clarify the relationship between logarithms and exponents (the power to which a number is raised). That was the work of Welsh mathematician William Jones, famous for being first to use $\pi$ for the ratio of a circle's circumference to its diameter. Jones's contribution to Napier's work was unearthed only in 1771, long after his death, when Royal Society librarian John Robertson reported that the Welshman had formulated the law of logarithms, $\log (a b)=\log (a)+\log (b)$. This is exactly the relationship that Napier had sought to make calculations less tedious. Although developed to simplify computations, logarithms turned out to be of supreme importance for pure and applied mathematics, and for all branches of science, from physics and chemistry to psychology, information theory, computer science and economics.

Unfortunately, Havil, like Napier, keeps the reader in the dark about the essential nature of logarithms for most of the book. It would have been helpful to introduce logarithms in the way taught to most secondary students now - as functions that solve for exponents in simple equations - and move on from there. Furthermore, interminable computations, laid out in minute detail often over several pages, may discourage many readers; and the narrative suffers from the frequent use of long quotations in seventeenth-century English. Nevertheless, John Napier fills a gap concerning an important, and often ignored, chapter of mathematical history.

George Szpiro is New York correspondent for the Swiss newspaper Neue Zürcher Zeitung. e-mail: georgeszpiro@gmail.com 